\title{
Data assimilation of dust aerosol observations for the CUACE/dust forecasting system
}

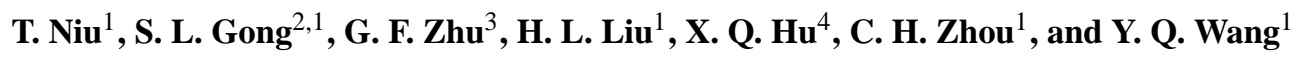 \\ ${ }^{1}$ Center for Atmosphere Watch \& Services (CAWAS), Chinese Academy of Meteorological Sciences, \\ China Meteorological Administration (CMA), Beijing 100081, China \\ ${ }^{2}$ Air Quality Research Division, Science \& Technology Branch, Environment Canada 4905 Dufferin Street, \\ Toronto, Ontario M3H 5T4, Canada \\ ${ }^{3}$ State Key Laboratory of Severe Weather, Chinese Academy of Meteorological Sciences, China Meteorological \\ Administration (CMA), Beijing 100081, China \\ ${ }^{4}$ National Satellite Meteorological Center, China Meteorological Administration (NSMC/CMA), Beijing 100081, China
}

Received: 5 April 2007 - Published in Atmos. Chem. Phys. Discuss.: 14 June 2007

Revised: 28 May 2008 - Accepted: 31 May 2008 - Published: 2 July 2008

\begin{abstract}
A data assimilation system (DAS) was developed for the Chinese Unified Atmospheric Chemistry Environment - Dust (CUACE/Dust) forecast system and applied in the operational forecasts of sand and dust storm (SDS) in spring 2006. The system is based on a three dimensional variational method (3D-Var) and uses extensively the measurements of surface visibility (phenomena) and dust loading retrieval from the Chinese geostationary satellite FY-2C. By a number of case studies, the DAS was found to provide corrections to both under- and over-estimates of SDS, presenting a major improvement to the forecasting capability of CUACE/Dust in the short-term variability in the spatial distribution and intensity of dust concentrations in both source regions and downwind areas. The seasonal mean Threat Score (TS) over the East Asia in spring 2006 increased from 0.22 to 0.31 by using the data assimilation system, a $41 \%$ enhancement. The forecast results with DAS usually agree with the dust loading retrieved from FY-2C and visibility distribution from surface meteorological stations, which indicates that the 3D-Var method is very powerful by the unification of observation and numerical model to improve the performance of forecast model.
\end{abstract}

\section{Introduction}

Simulation and forecasts of sand and dust storms (SDS) have been progressed significantly in the last decay to address the issues related to climate changes and air quality

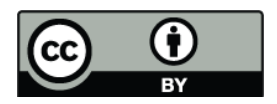

Correspondence to: $\mathrm{T}$. Niu (niutao2001@cams.cma.gov.cn) impacts (Levin et al., 1996; Tegen and Fung, 1995; Zender et al., 2003). Several regional dust models have been applied for ACE-Asia field observation periods (Gong et al., 2003b; Huebert et al., 2003; Uno et al., 2004; Zhao et al., 2003) and reasonable simulated results have been reported. Nevertheless, a current study of the dust model inter-comparison project (DMIP) pointed out the status of current regional dust models when applied to the Asian domain (Uno et al., 2006). It was found that dust transport patterns from the emission source region are usually very similar, but the predicted surface level concentrations sometimes show discrepancies of more than two orders of magnitude. The differences in treating the dust emission schemes, surface boundary data (e.g., soil texture, soil wetness, and land-use data including recent desertification information), and atmospheric models (meteorological and transport models) are speculated as the major source of the discrepancies. For those reasons, methods for the unification of observations and model predictions will play a salient role in improving dust forecasting capabilities.

Data assimilation is the best method to unify observation and model prediction. It has been shown that data assimilation is very powerful in improving meteorology forecasting accuracy. (Kalnay, 2003) by supplying reasonable initial fields to dynamical models. Because of model uncertainties in parameterizing physical processes, errors will result as the simulation length increases. Data assimilation can estimate and correct these errors to some degrees. Meanwhile, data assimilation can extrapolate information to some areas and some model components even without observation. In addition, a reasonable initial field offered by a data assimilation scheme will make the different components of model in harmony. Therefore a dynamical model system should have a data assimilation system that fits it. There are a variety

Published by Copernicus Publications on behalf of the European Geosciences Union. 


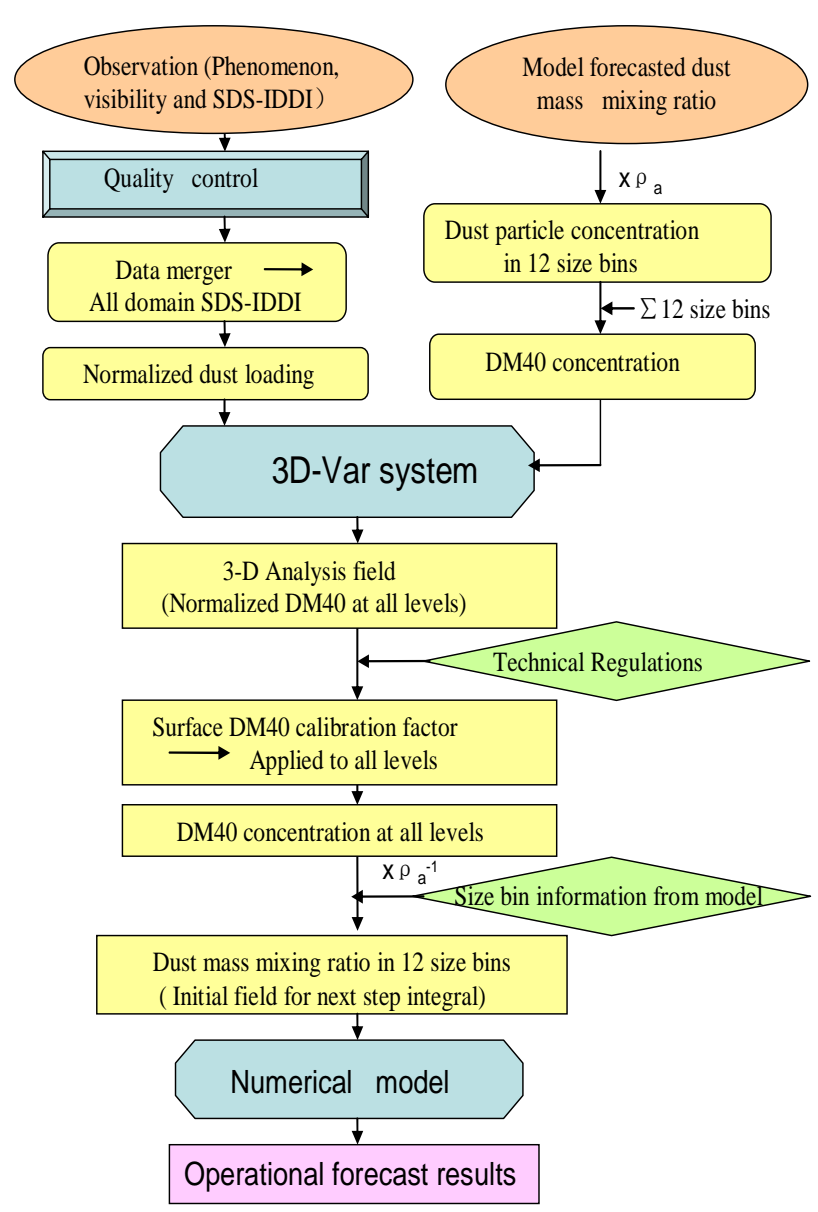

Fig. 1. Schematic presentation of the four functional groups and flowchart of the DAS.

of algorithms to deal with the data assimilation problem (Bengtsson, 1981; Lorenc 1986, 1997; Daley, 1991; Bennett, 1997). The examples of general methods include nudging method, optimal interpolation (OI), 3-dimensional variation (3D-Var). More advanced methods include 4-dimensional variation (4D-Var), extended Kalman Filter and ensemble Kalman Filter. Menard (2000a, 2000b) assimilated chemical tracer observation in stratospheric using a Kalman Filter. William et al. (2001) developed a system for forecasting aerosol optical depth (AOD) by coupling a chemical transport model with a system for assimilating satellite retrievals of AOD. Recently, 4D-Var method has been applied to chemical transport model (CTM) for inverse modeling. For example, Hakami et al. (2005) estimated black-carbon emissions over eastern Asia using the adjoint STEM model. Yumimoto and Uno (2006) applied 4D-Var to a CTM and estimated CO emissions over the East Asian region. Most recent developments and results of chemical adjoint are presented by Henze and Seinfeld (2006).

Assimilation of dust aerosols is just in its early stage due to the lack of enough observational data sets. Using the To- tal Ozone Mapping Spectrometer (TOMS) aerosol index (AI) data as the initial dust loading input for a dust prediction system, Alpert et al. (2002) has found a positive improvement for the model performance. This demonstrates the importance of an accurate initial dust concentration even though no data assimilation was used. In a 4D-Var approach, a factor in the dust emission parameterization scheme was assimilated by using the lidar vertical profiles of dust aerosols (Yumimoto et al., 2007). Under-estimates in the dust emission flux were corrected and more reasonable dust concentration was achieved.

However, applications of $4 \mathrm{D}$-Var remain limited as it is quite expensive for computation and not easy for system upgrade due to a close link on an adjoint model which is the inverse of the forecast model. Up to now 3D-Var method plays an important role in weather and climate studies and operational forecast since it was first applied to the assimilation of observational data in 1981 (Bengtsson, 1981). Considering the situation of the computer resource and operational requirement, a 3D-Var method was chosen to establish the SDS Data Assimilation System (SDS-DAS) in China.

This paper presents the development of the SDS-DAS and its application in spring 2006 SDS operational forecasts in East Asia. Real-time measurements of dust aerosols from surface meteorological stations (visibility and phenomena) and spatial coverage from the Chinese geostationary satellite FY-2C have been integrated into a unified data system for the forecast of dust aerosols through the SDS-DAS.

\section{Brief description of the SDS-DAS}

Based on the work of Lorenc (1986, 1997) and Barker (2003), CAMS (Chinese Academy of Meteorological Sciences) developed a three dimensional variation data assimilation system (Zhang et al., 2004; Zhuang et al., 2005) for the Chinese weather forecast model (GRAPES). This study extends the assimilation scheme in GRAPES to assimilate visibility and satellite retrieval dust loading data for a SDS forecast system -CUACE/Dust. The SDS-DAS contains four functional groups: (1) observational data quality control (QC), (2) observational data merger (statistic analysis), (3) 3D-Var analyses method and (4) post-processor to the CUACE/Dust. Figure 1 is a schematic description and flowchart of the DAS with different shapes of the blocks to show the different leading processes. Details of each function group are discussed below.

\subsection{Observational data}

Observational data used in the SDS-DAS include the routine observational data of a SDS from regular meteorological stations and satellite remote sensing data. For different data types, different quality control subsystem (QC) was used to admit the data into the DAS. 


\subsubsection{Satellite retrieval data}

Satellite retrieval data are widely used in recent years for its advantages of high spatio-temporal resolutions. The satellite data used in this DAS was obtained by the National Satellite Meteorological Center (NSMC) of CMA. Based on the Chinese FY-2C remote sensing data, NSMC established an automatic identification and real-time retrieving system for the dust aerosols through combining the separating-window and spectrum gathering methods. A detailed description of the retrieval methodology and reliability was given by $\mathrm{Hu}$ et al. (2008). This data reflecting the dust aerosol column loading was named SDS-IDDI (Infrared Difference Dust Index), a dimensionless quantity between 0 and 50. The temporal resolution of SDS-IDDI is an hour with a spatial resolution of $5 \mathrm{~km} \times 5 \mathrm{~km}$. A value of IDDI between 0 and 10 usually indicates a clear sky, 10-20 a floating dust (FD), 20-30 a blowing dust (BD), 30-40 a SDS event and 40-50 a severe SDS event. In the spring of 2006, there were total 31 SDS processes in the northeastern Asia (Yang et al., 2008) and the satellite always presented clear images of a SDS process (excepting the cloudy cover area).

\subsubsection{Surface regular meteorological station data}

There are more than 2500 surface meteorological stations in China. The real-time weather phenomena and visual visibility are observed and reported every three hours according to the WMO standard.

Figure $2 \mathrm{a}$ shows the weather phenomena from the surface meteorological stations and Fig. 2b presents the satellite SDS-IDDI at the same time. The results showed that the SDS took place in the middle and southern part of the Mongolia, the most part of Inner Mongolia, Gansu province, and Ningxia, as well as in the middle and southern part of Xinjiang, with various intensities, such as FD, BD, SDS and severe SDS. However, the satellite images (Fig. 2b) revealed that large areas were covered by the clouds, including Xinjiang, Gansu, the western part of Inner Mongolia. Therefore SDS-IDDI failed to reflect SDS information over these regions. Figures $2 \mathrm{a}$ and $2 \mathrm{~b}$ clearly demonstrated that a complete picture of the SDS distribution should include both the satellite data and surface data. Therefore, the data assimilation system makes use of the real-time weather phenomena observed by surface meteorological stations to complement the satellite data. The detail is in Sect. 2.1.4.

Additionally, according to the technique regulations of SDS monitoring of China (CMA, 2006), the FD, BD, SDS and severe SDS are translated into corresponding dust concentrations of 0-2000, 2000-5000, 5000-20000 and $>20000 \mu \mathrm{g} \mathrm{m}^{-3}$, respectively.

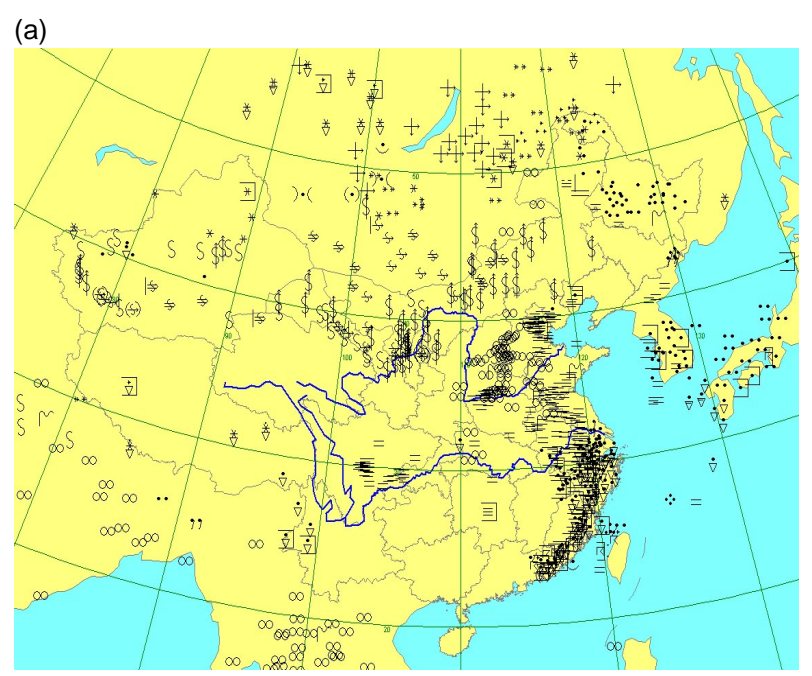

(b)

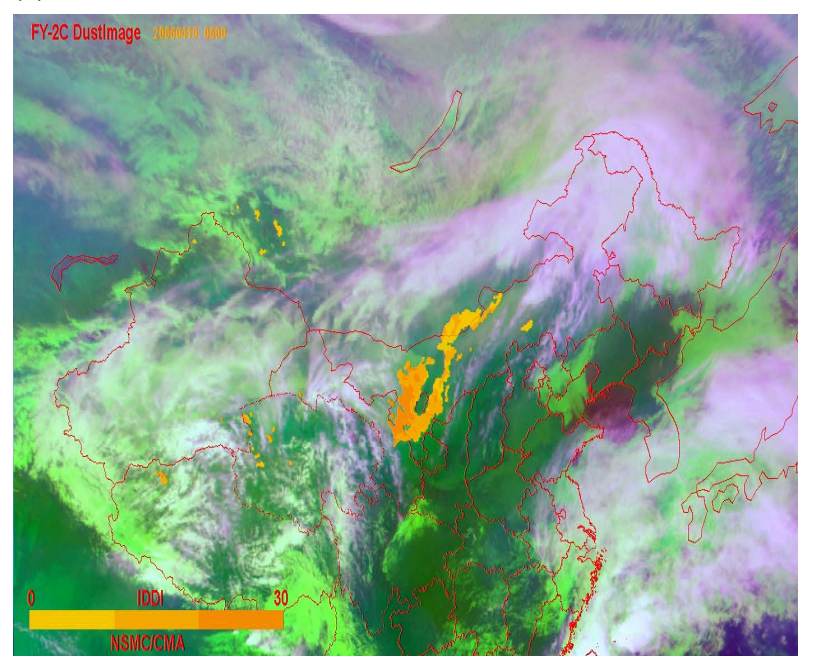

Fig. 2. (a) Observations of SDS phenomena from the surface meteorological stations and (b) SDS_IDDI (yellow area). The time is 06:00 GMT on 10 April 2006. The symbols of "s", "\$”, "§", "s"indicate floating dust (FD), blowing dust (BD), SDS and severe SDS, respectively

\subsubsection{Data quality control (QC)}

All observation data come with various errors, including random errors, systematic errors, and gross error. Usually, it's difficult to distinguish them. For a detailed discussion, please refer to Lorenc (1986). Before the data assimilation, data with gross errors should be removed, and the data with systematic errors should be corrected. The commonly used QC methods include the check of weather consistency and the spatial continuity. For the QC of satellite retrieval data, please refer to the article by $\mathrm{Hu}$ et al. (2008).

Because of the typical local characteristics of SDS weather, the QC in this DAS refers to the check of weather 
(a)

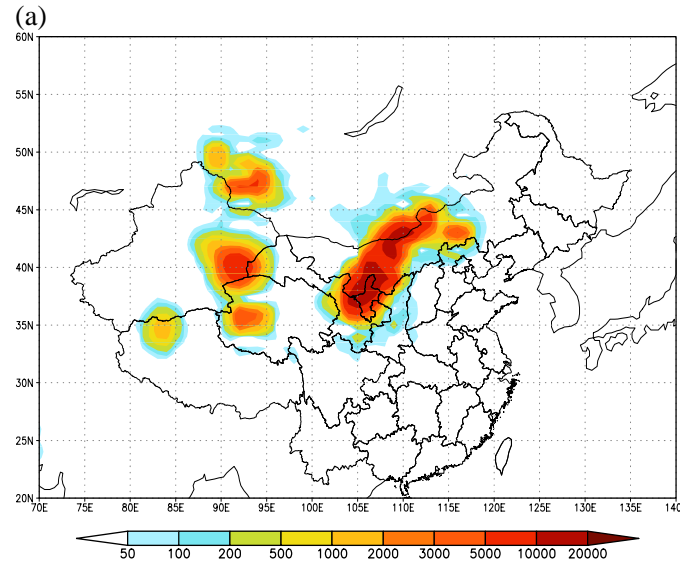

(c)

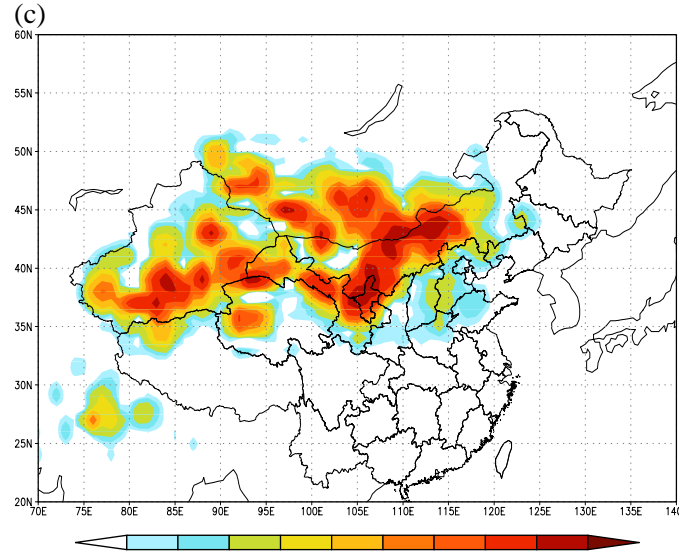

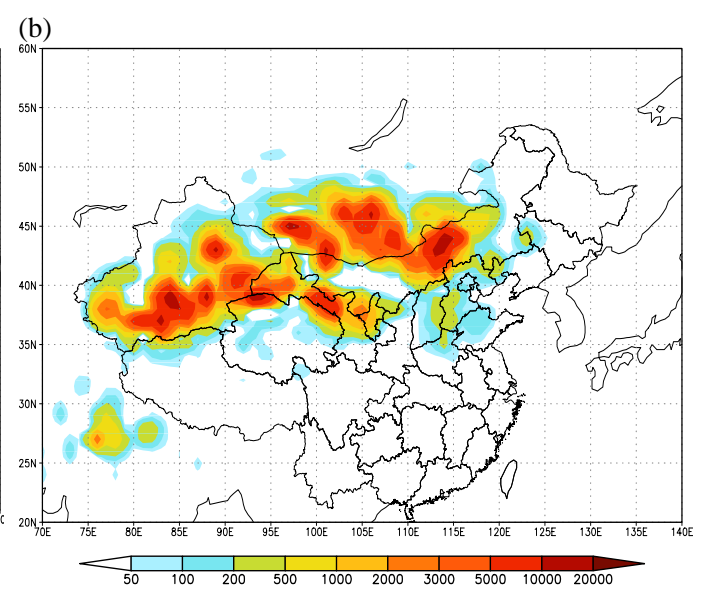

Fig. 3. Analysis dust concentration results at 14:00 GMT on 10 April 2006 for three types of DAS experiments by using (a) only SDS_IDDI, (b) only visibility and (c) both SDS_IDDI and visibility

consistency, i.e., checking if the weather phenomena of SDS are consistent with the visibility classification based on the observation regulations for the sand-dust weather prescribed by WMO. If the data pass the check of weather consistency, it is adopted by DAS. Otherwise, the data are removed.

\subsubsection{Estimation of all domain SDS-IDDI}

In those area where no SDS-IDDI was reported by the satellite due to clouds or missing data but a SDS phenomenon was reported by the surface regular meteorological station, the surface visibility data was converted into SDS-IDDI based on a statistical relationship (Hu et al., 2008). According to $\mathrm{Hu}$ et al. (2008), the relationships between the SDS-IDDI and the visibility is an exponential function with a locationdependent coefficient. A database of the fitting coefficients has been generated for use in CUACE/Dust for all regions in Asia from this study. Finally, the IDDI is normalized into a relative strength of dust loading in the domain with values between 0-100 and ready for use in the SDS-DAS system (Fig. 1).

\subsection{SDS 3D-Var assimilation system}

\subsubsection{D-Var analysis method}

The main task of 3D-Var is to find the minimum of objective function $J(x)$

$$
\begin{aligned}
J(x) & =\frac{1}{2}\left[\left(x-x_{b}\right)^{T} \mathbf{B}^{-1}\left(x-x_{b}\right)\right. \\
& \left.+\left(H(x)-\mathbf{y}_{o}\right)^{T} \mathbf{O}^{-1}\left(H(x)-\mathbf{y}_{o}\right)\right]
\end{aligned}
$$

where $x$ is the analysis field of dust concentration, $x_{b}$ the background field of dust concentration provided by model, $\mathbf{B}$ the background error covariance matrix, $\boldsymbol{y}_{o}$ the observation (in this study $\boldsymbol{y}_{o}$ is normalized dust loading) and $\mathbf{O}$ the observation error covariance matrix. $H$ is the observation operator matrix that transfers the variables from model space to observational space. When $J$ goes to the minimum, $x_{a}$ is the optimized estimate of $x$.

The objective function $J$ is the sum of the two terms. The first term, called background term, represents a departure of the assimilated value $x$ from the first guess field $x_{b}$, weighted by the background error covariance matrix $\mathrm{B}$. The 
second term, called observation term, represents a departure between simulated and observed values weighted by the observation error covariance matrix $O$. It is obvious that the effect of an assimilation system will rely on how to define $\mathrm{B}$ and $\mathrm{O}$. The characteristic of $\mathrm{B}$ is described in detail later. Generally, it is also very difficult to obtain $\mathrm{O}$ exactly and so $\mathrm{O}$ is defined as a diagonal matrix, which indicates there is no correlation between observations. Otherwise, it will cause a lot of trouble in the minimization process. The minimization of the objective function $J$ is performed through an iterative process using Quasi-Newton limited memory BFGS scheme (Liu, 1989). Negative values of dust concentration are replaced with zero at the end of analysis.

\subsubsection{Background error covariance matrix B}

The background error covariance matrix B is important to the analysis system, which controls how the information from the observation influences the value of model grids nearby the observational position. A statistical harmonious correction is given via $\mathrm{B}$ to the model grid nearby observational position in order to make sure the dynamical harmony of model variables. However the background error covariance cannot be calculated accurately because the true situation of the atmosphere cannot be known. Usually, the following three methods are used to solve this problem. 1) Observation method or Hollingsworth-Lonnberg (1986) method; 2) NMC method (Parrish and Derber, 1992); 3) Analysis ensemble method (Fisher, 2001).

Normally covariance matrix B is defined as

$$
\begin{aligned}
& \mathrm{B}=\left(\begin{array}{ccccc}
s_{11} & s_{12} & \cdots & s_{1 j} & \cdots \\
\vdots & \ddots & & \vdots \\
\vdots & & s_{i j} & & \vdots \\
\vdots & & & \ddots & \vdots \\
s_{n 1} & s_{n 2} & \cdots & s_{n j} & \cdots
\end{array}\right) \\
& =\left(\begin{array}{ccccc}
\sigma_{1}^{2} & \sigma_{1} \sigma_{2} r_{12} & \cdots & \sigma_{1} \sigma_{j} r_{1 j} & \cdots \\
\vdots & & & & \vdots \\
\vdots & \ddots & \sigma_{i} \sigma_{j} r_{i j} & & \vdots \\
\vdots & & & \ddots & \vdots \\
\sigma_{n} \sigma_{1} r_{n 1} & \sigma_{n} \sigma_{2} r_{n 2} & \cdots & \sigma_{n} \sigma_{j} r_{n j} & \cdots
\end{array}\right)
\end{aligned}
$$

where $s_{i j}$ is the covariance between $i^{\text {th }}$ and $j^{\text {th }}$ grid. $\sigma_{i}$ and $\sigma_{j}$ is variance of $i^{t h}$ and $j^{t h}$ grid respectively. $r_{i j}$ is correlation coefficient between $i^{t h}$ and $j^{t h}$ grid. In this scheme, the background error covariance is hypothesized separable in horizontal and vertical directions, i.e., $r_{i j}$ can be divided into $R_{h}$ and $R_{v}$. This means horizontal structure of covariance does not have a relationship with the vertical coordinate. Hollingsworth-Lonnberg (1986) discussed the rationality of this hypothesis. Generally, a Gaussian function is adopted in horizontal. Hypothesizing the distribution of background error covariance is horizontally homogeneous
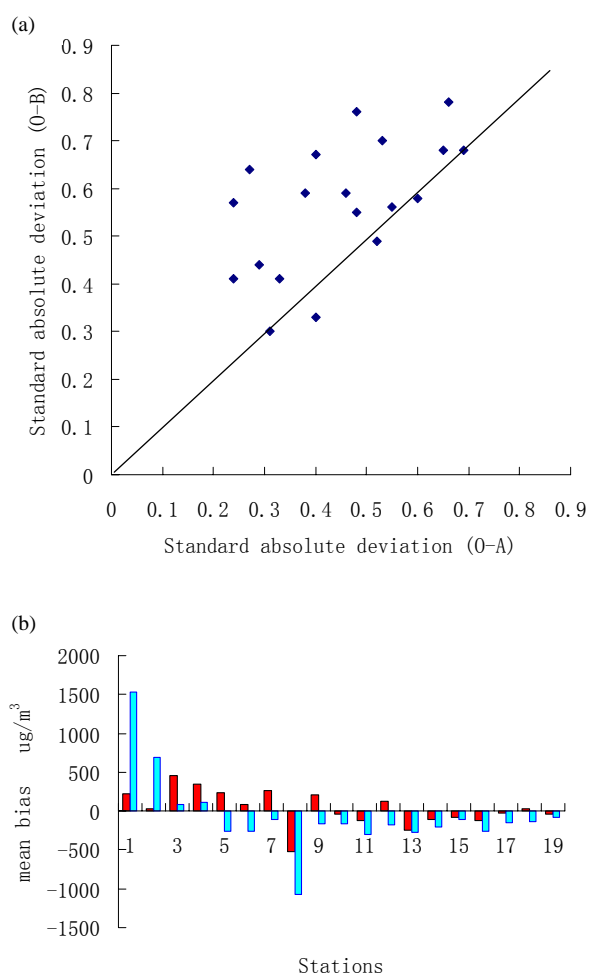

Fig. 4. Evaluation of the 3D-Var assimilation system against surface $\mathrm{PM}_{10}$ observations. (a) Standard absolute deviation of O-B and OA for each stations, 1 March - 31 May 2006. (b) Mean bias of O-B and O-A for each stations, 1 March - 31 May 2006. The blue bars are O-B and the red bars are O-A, (unit: $\mu \mathrm{g} / \mathrm{m}^{3}$ ).

and isotropic. Therefore, the backgrounds error covariance of any two points under spherical-surface coordinate is a function that only depends on the distance. It is represented by the following function:

$R_{h}(d)=e^{-d^{2}} / 2 L^{2}$

Where $d$ is the distance between any two points, $L$ is the horizontal correlation length scale. Using a least square method to fit the parameter $L$ in the Gaussian function, a value of $L=150 \mathrm{~km}$ is obtained and used in CUACE/Dust system.

In the vertical, logarithms function is adopted and the correlation structure function in the vertical is given as:

$R_{v}=\left(1.0+k p\left(\log h_{i}-\log h_{j}\right)^{2}\right)^{-1}$

where $k p$ is the correlation length scale in the vertical, $h_{i}$ and $h_{j}$ are the heights of $i^{t h}$ layer and $j^{t h}$ layer, respectively.

After determining the relation function for the vertical and horizontal directions, the NMC method (Parrish and Derber, 1992) is used to determine the $\sigma_{i}$ which is another key factor to determine B: Defined:

$\varepsilon_{i k}=x_{i k}^{48}-x_{i k}^{24}$ 
(a)

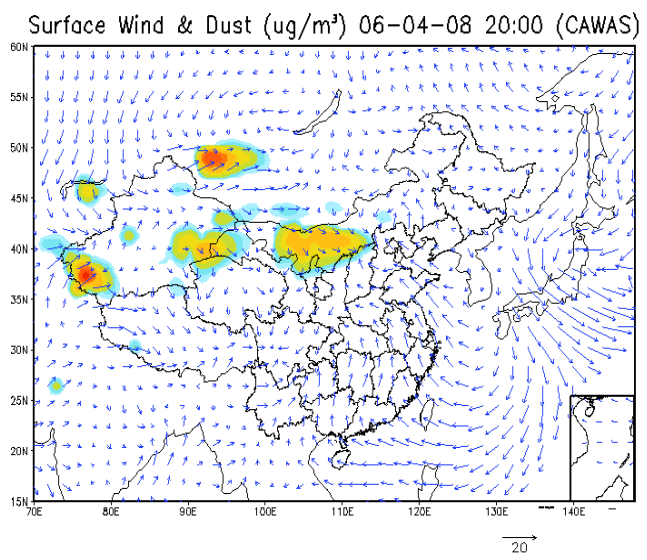

(b)

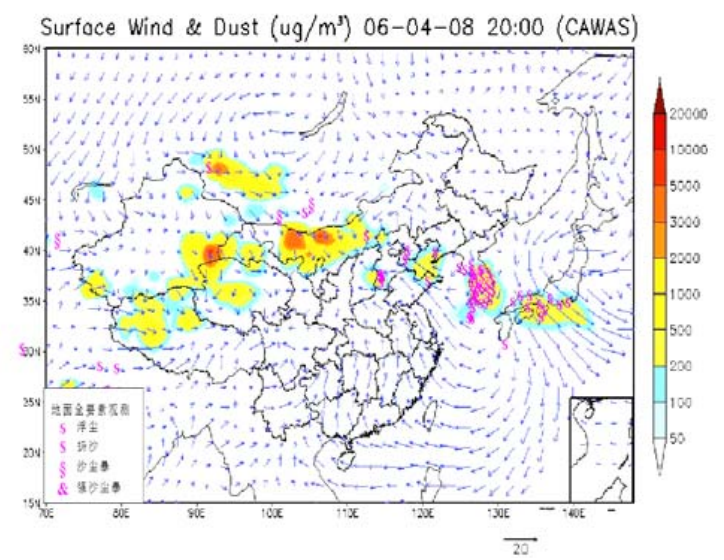

Fig. 5. The forecasted dust concentrations by CUACE/Dust using (a) an ideal initial conditions and (b) a DAS generated initial condition and with surface observations. Case 8 April 2006. The symbols of "S", "\$", "§", "\&" are defined in Fig. 2.

$\bar{\varepsilon}_{i}=\frac{1}{m} \sum_{k=1}^{m} \varepsilon_{i k}$

$\sigma_{i}=\left[\frac{1}{m} \sum_{k=1}^{m}\left(\varepsilon_{i k}-\bar{\varepsilon}_{i}\right)^{2}\right]^{\frac{1}{2}}$

where $x_{i k}^{48}, x_{i k}^{24}$ are the values on $i^{\text {th }}$ grid forecasted by model with lead time of 48 and $24 \mathrm{~h}$, respectively. $k$ is the sample sequence and $m$ is the sample size. When enough samples are available, $\sigma_{i}$ can be estimated and then some mean methods including zonal mean, height mean were adopted to satisfy the dynamical harmony of model. Finally, the matrix B can be established.

Furthermore, Recursive Filter is used to perform the horizontal transform, EOF is used to solve eigenvalue to perform the vertical transform in order to substitute the calculation of $\mathrm{B}^{-1}$. A detail discussion refers to Barker et al. (2003, 2004). Through the two transforms in horizontal and vertical directions, the model variables were transformed to control variables in order to benefit to the minimization. Each stage of the control variable transforms is discussed in detail in Barker et al. $(2003,2004)$.

\subsection{Interface to the CUACE/Dust}

The CUACE/Dust system (Gong and Zhang, 2008) was developed based on a size-segregated dust aerosol module CAM (Canadian Aerosol Module) (Gong et al., 2003a) that was coupled into a mesoscale meteorological model - MM5 to conduct the real time SDS forecasting for Northeast Asia. The prognostic variables are the dust mass mixing ratio in twelve size bins (Zhou et al., 2008) at all 23 model layers. Since the SDS-IDDI retrieved from FY-2C reflects the dust column loading, all the modeled dust mass mixing ratios in (a)

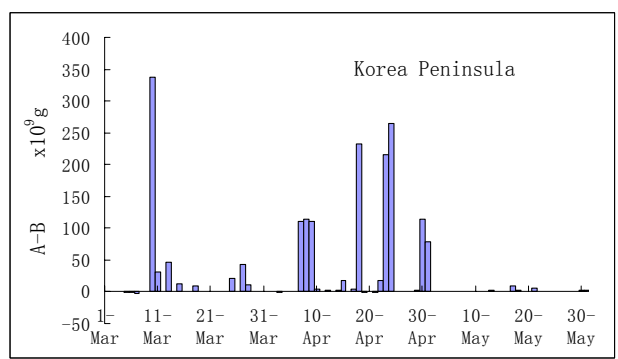

(b)

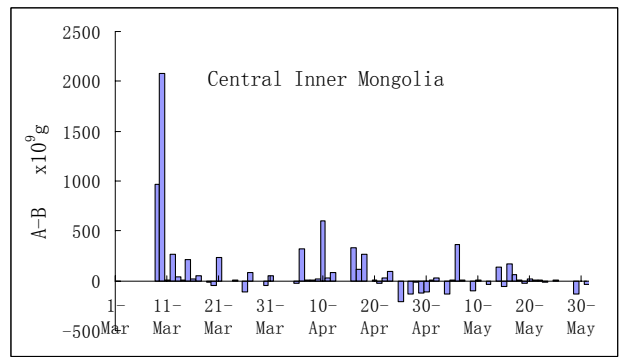

(c)

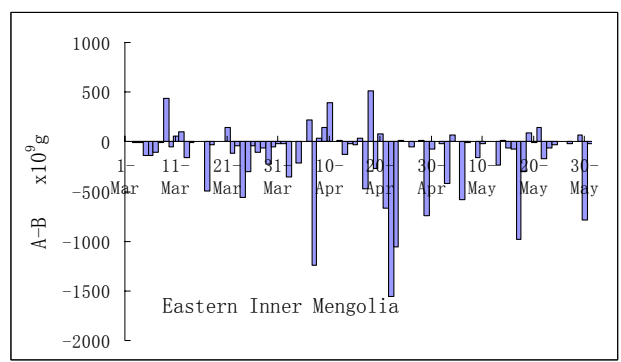

Fig. 6. Corrections of DM40 column loading in spring 2006 by the DAS in (a) Korea Peninsula, (b) central Inner Mongolian and (c) eastern Inner Mongolia 
(a)

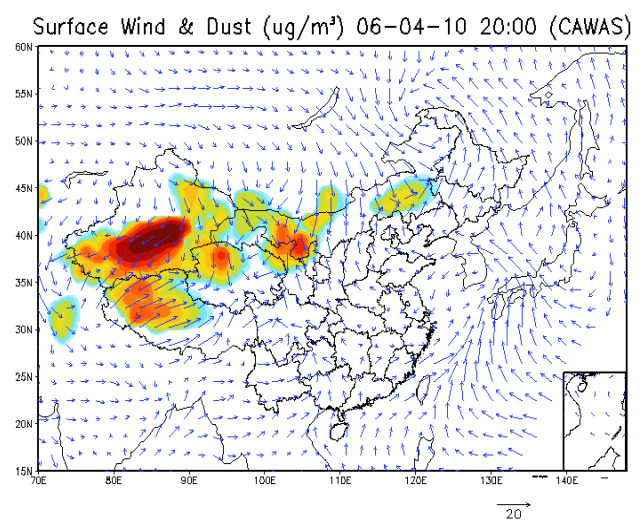

(b)

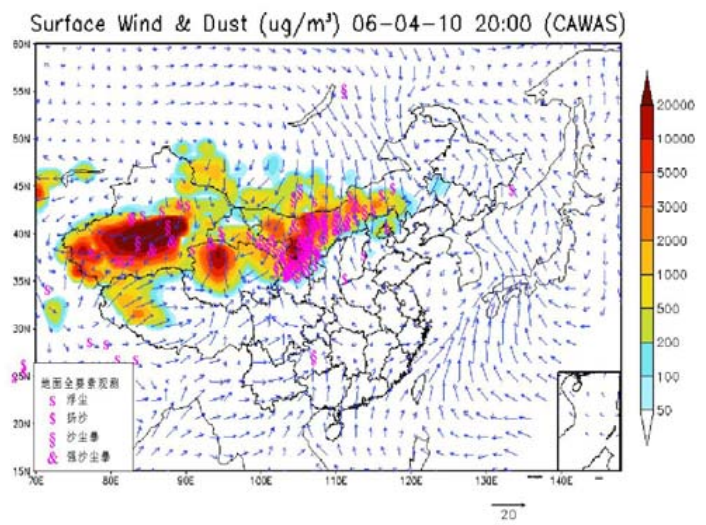

Fig. 7. The forecasted dust concentrations by CUACE/Dust using (a) an ideal initial conditions and (b) a DAS generated initial conditions and with surface observations. Case 10 April 2006. The symbols of "S", "\$”, "§", “\&” are defined in Fig. 2.

(a)

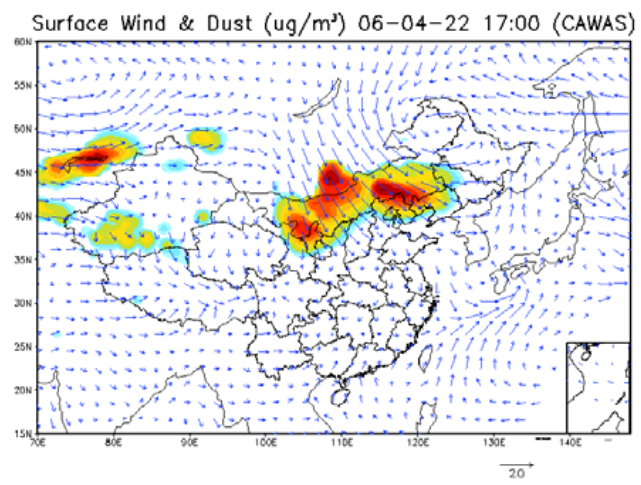

(b)

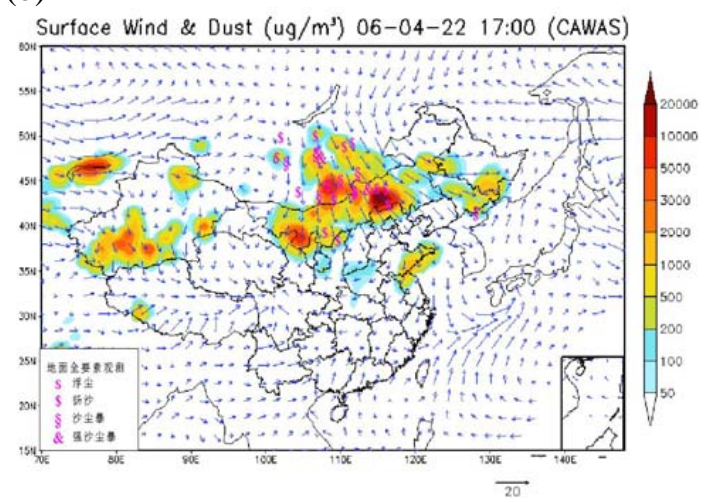

Fig. 8. The forecasted dust concentrations by CUACE/Dust using (a) an ideal initial conditions and (b) a DAS generated initial conditions and with surface observations. Case 22 April 2006. The symbols of "S", "\$”, "§", "\&" are defined in Fig. 2.

each layer are integrated to obtain the total simulated dust column loading and the loading is then normalized into dimensionless scale as the SDS-IDDI was normalized. These processes are performed by the observation operator matrix $H$. The vertical profile information from the model are retained for converting back the vector in observation space to model space by the adjiont matrix $H^{\prime T}$.

After minimizing by the 3D-Var scheme, a dimensionless DM40 distribution from the model has been assimilated with the observation data sets. Since each class SDS obtained from surface station has a dust concentration associated with it (Sect. 2.1.2), a calibration factor is obtained for the surface layer analysis SDS (DM40) dimensionless distribution to be aligned with the surface observed concentration values. Then this factor is applied to all the layers to completely convert the 3-D dimensionless distribution into DM40 concentration. Then the size bin distribution information from the model is used for converting analysis DM40 to dust particle concentration in 12 size bins, which are used as the integral initial field for the next step simulation. A detailed flowchart is given in Fig. 1.

\section{Assimilation experiments}

\subsection{Sensitivity test}

To investigate the effect of the SDS-DAS system on forecasting results, three types of experiments were conducted with: 1) satellite data only; 2) visibility data only and 3 ) both of them. The case chosen for the experiment was a severe SDS occurred on 10 April 2006 (Fig. 2).

Figure $3 \mathrm{a}$ is the analysis field only using SDS-IDDI by the DAS, which agrees with Fig. 2b. Due to heavy cloud covers, Nanjiang (south Xinjiang) basin, central-west of Gansu province and Mongolia did not show any SDS by the satellite. These missed regions were reported SDS by the surface 


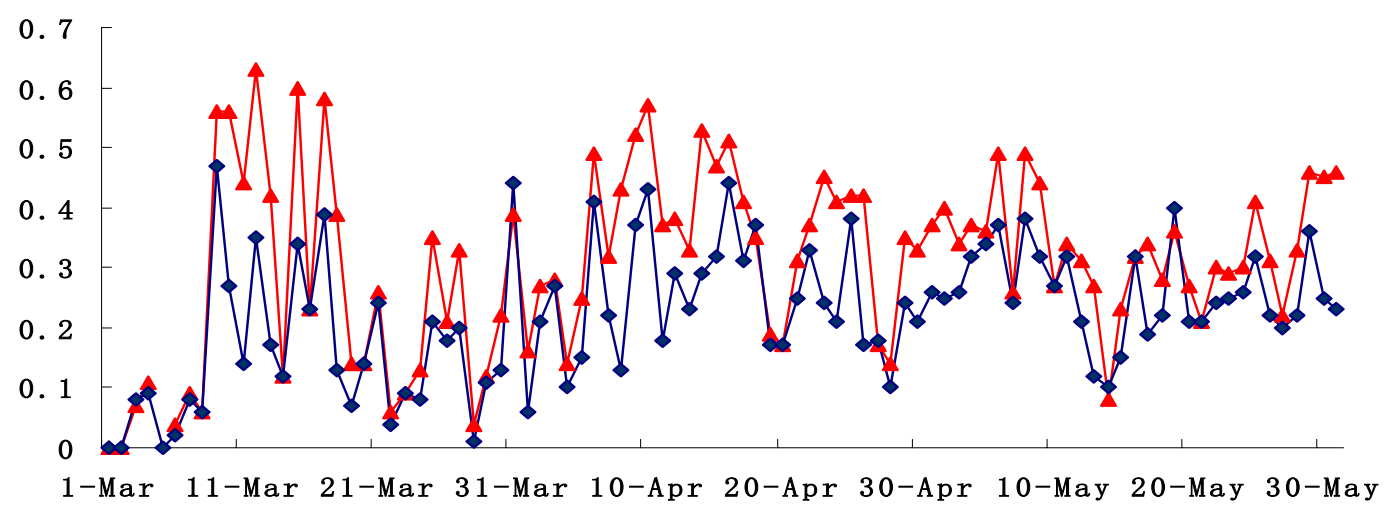

Fig. 9. Daily Threat Score (TS) during the period of spring 2006. The line with triangle (red) is the daily TS with DAS in CUACE/Dust. The line with diamond (black) is the daily TS without DAS in CUACE/Dust.

meteorological stations as was indicated by the analysis field just using visibility data by the DAS (Fig. 3b). Therefore, the meteorological station data provide complementary information to the IDDI in those areas covered by clouds.

Finally, Fig. 3c shows the analysis field using both visibility and SDS-IDDI data by the DAS. Apparently, this result presents a more complete picture of SDS than any of the two observations alone. In the operational forecast using CUACE/Dust, a combination of station and satellite data is used in the DAS. A detail discussion about how the DAS improves the general dust model performs is given in Sect. 4.1.

\subsection{Evaluation of the DAS}

The CUACE/Dust simulates the total dust mass concentration with a diameter less than $40 \mu \mathrm{m}$ (DM40) by 12 size bins while the current observation net work (China SDS Net) only measures the $\mathrm{PM}_{10}$ (Wang et al., 2008). According to the size bin configuration of the model, $\mathrm{PM}_{10}$ was obtained by summing up the concentrations in the size bin from 1 to 8 and used to verify the DAS quantitatively. Figure 4a shows the standard absolute deviation of O-B and O-A from 1 March 31 May 2006. O-B stands for observation $\mathrm{PM}_{10}(\mathrm{O})$ minus forecasting $\mathrm{PM}_{10}$ without DAS (B). O-A stands for observation $\mathrm{PM}_{10}(\mathrm{O})$ minus analysis forecast $\mathrm{PM}_{10}$ with DAS (A). The units all of them are $\mu \mathrm{g} / \mathrm{m}^{3}$. Most of dots are above the diagonal line indicating a reduction of standard absolute deviation by the DAS. Figure $4 \mathrm{~b}$ further illustrates the mean bias of O-B and O-A, showing a deceasing bias for most of the 19 stations by the DAS.

All of them reveal the error statistics characteristics of forecast $\mathrm{PM}_{10}$ with and without the DAS. It can be observed that most of the stations used to evaluate the DAS obtain a reduction of both standard deviation and bias as a result of the analysis. That means DAS improve the capability of forecast model.

\section{Impacts of assimilation on the CUACE/Dust forecast- ing system}

\subsection{Case studies of SDS forecast improvements by DAS}

In spring 2006, the CUACE/Dust was used as the operational dust forecasting system in China with the DAS. Figure 5 shows the forecasting results for the 5-9 April severe SDS with (Fig. 5b) and without (Fig. 5a) the DAS. Comparing these two results, it can be found that DAS has a substantial influence on the results of CUACE/Dust not only on the intensity but also on the position and areas covered. In this case, the SDS transported to Korea and the southern part of Japan on 8 April 2006 and maintained there for 2 days. The forecasts with DAS agreed with this fact (Fig. 5b), but the forecasts without DAS couldn't predict this phenomenon (Fig. 5a). This demonstrates that the DAS plays a very important role for forecasting the SDS in the downwind areas far away from the source regions.

Figure 6a shows the correction of column dust mass loading of DM40 up to $3000 \mathrm{~m}$ by the DAS over the Korea Peninsula $\left(35^{\circ} \mathrm{N}-41^{\circ} \mathrm{N}, 125^{\circ} \mathrm{E}-129^{\circ} \mathrm{E}\right)$. This correction is expressed as the difference of the forecasted column loading with DAS (A) and without DAS (B) in spring 2006. It is found that the corrections are almost positive, especially during 10-12 March, 7-9 April, 18 April, 23-24 April, 30 April - 1 May. Compared with surface observations, it is clear the DAS has corrected the forecasts to bring the CUACE/Dust results more agreeable to the real situations during these periods when FD or BD phenomena did occur over Korea Peninsula. This also reflects some weakness in the CUACE/Dust to transport SDS over a long distance and significant improvement of the DAS to alleviate such problems.

The DAS also improved the forecasts at the source regions. Figure 7 shows a case on 9-11 April 2006 when a severe SDS occurred in the source regions. Comparing Fig. 7a and 7b, it can be found that the forecasts with DAS agreed with the surface observations while the forecasts without DAS were much weaker and missed a lot of regions, especially in the 
middle part of Inner Mongolia and southern Outer Mongolia. Figure $6 \mathrm{~b}$ shows the corrections for central Inner Mongolian source region $\left(38^{\circ} \mathrm{N}-43^{\circ} \mathrm{N}, 108^{\circ} \mathrm{E}-113^{\circ} \mathrm{E}\right)$. The corrections are positive, especially during 9-10 March, 6 April, 10 April, 16-18 April and 6 May. This case illustrates the improvement by the DAS in the forecasts for the source regions where the dust emission is not accurately predicted by the model.

The final case was for a SDS that was over-predicted by the CUACE/Dust without the DAS initial conditions (Fig. 8a). A common strength SDS occurred on 22 April 2006. Comparing these two predictions (Figs. $8 \mathrm{a}$ and $8 \mathrm{~b}$ ), it can be found that DAS has revised the results of CUACE/Dust forecasts not only to the intensity but also to the positions and areas covered. In this case, the CUACE/Dust without DAS forecasted that a SDS would arrive in Beijing and Tianjin at 09:00 GMT 22 April 2006. With the DAS, the forecast showed that a SDS would just arrive in northern Hebei province and would not arrive in Beijing, which agreed with surface observations. Another correction was made for North-East China and Shandong province. This overestimate can be shown from the correction plot of the column DM40 loading in Fig. $6 \mathrm{c}$ for the eastern part of Inner Mongolia $\left(42^{\circ} \mathrm{N}-46^{\circ} \mathrm{N}, 113^{\circ} \mathrm{E}-118^{\circ} \mathrm{E}\right)$. It is found that the values are mostly negative, especially during 24-25 March, 7 April, 21-23 April, 17-18 May and 30 May. Comparing these with surface observations it can be found that during these periods in the eastern Inner Mongolia the SDS phenomena were not as strong as forecasted. This implies that the DAS can correct the over-estimate of dust source strength as well.

\subsection{Forecast verification - Threat Score (TS)}

Threat score (TS) is a statistical method to verify the forecast quality prescribed by WMO. For the entire season of spring 2006, the CUACE/Dust forecasting results were verified against observations by a TS system (Wang et al., 2008). Figure 9 shows a comparison of the daily TS (Yes/No forecast) for each $24 \mathrm{~h}$ forecast in spring 2006 with and without DAS in CUACE/Dust. A daily TS is based on a dichotomous forecast of SDS or non-SDS event. A SDS event includes FD, BD, SDS and severe SDS. Whenever there is a SDS event observed in a site and forecasted by the model in the same place, it is a "YES" otherwise it is a "NO". For most SDS processes, for example, 8-14 March, 23-25 March, 5-9 April, 20-25 April, 2-4 May, 29-30 May etc., the TS with DAS are much better than those without DAS. The seasonal mean TS increased from 0.22 without DAS to 0.31 with DAS, a $41 \%$ enhancement.

\section{Conclusions}

A DAS was developed within the frame work of CUACE/Dust to use the visibility and satellite retrieval dust loading data for the SDS forecasts. Sensitivity tests show that both satellite retrieval data and surface observation (visibility and phenomena) have the same importance for the SDS forecasts. A combination of them provided the best performance. A contrast analysis revealed that the 3D-Var method has made a major improvement for the capability of the model in forecasting short-term variability in the spatial distribution and intensity of dust concentration, especially in those areas far from the source regions. The TS increased $41 \%$ in spring 2006 by the DAS to reach a seasonal average of 0.31 .

However, a major component missing from the observations is the near real-time vertical profiles of the SDS. Surface lidar can provide vertical information for the data assimilation system, which should help to correct the vertical structures. In the future as more lidar observations become available and real time in Asia, lidar data will be adopted in the DAS.

Acknowledgements. The authors wish to thank for the financial supports from the National Basic Research Program (973) (2006CB403703 and 2006CB403701) and (2008BAC40B02) of China for this project.

Edited by: X. Y. Zhang

\section{References}

Alpert, P., Krichak, S. O., Tsidulko, M., Shafir, H., and Joseph, J. H.: A Dust Prediction System with TOMS Initialization, Mon. Weather Rev., 130, 2335-2345, 2002.

Barker, D. M., Huang, W., Guo, Y.-R., and Bourgeois, A.: A threedimensional variational (3DVAR) data assimilation system for use with MM5. NCAR Tech. Note. NCAR/TN-453 1 STR, 68 pp., (Available from UCAR Communications, P.O. Box 3000, Boulder, CO 80307.), 2003.

Barker, D. M., Huang, W., Guo, Y. R., Bourgeois, A. J., and Xiao, Q. N.: A three-dimensional variational data assimilation system for MM5: Implementation and initial results, Mon. Weather Rev., 132, 197-914, 2004

Bengtsson, L.: Dynamic Meteorology:Data Assimilation Method, Springer Verlag, 330 pp., 1981.

Bennett, A. F., Chua, B., and Leslie, L.: General inversion of global numerical weather prediction model(II). Analysis and implementation., Meteor. Atmos. Phys., 61, 129-140, 1997.

CMA: Technical regulations of sand and dust storm monitoring, Standarization Administration of the People's Republic of China, Beijing, 12 pp., 2006.

Daley, R.: Atmosphere Data analysis, Cambridge university press, Cambridge, 457 pp., 1991.

Fisher, M.: Assimilation techniques(1), 3D-Var, ECMWF meteorological training course lecture series, 220 pp., 2001.

Gong, S. L., Barrie, L. A., Blanchet, J.-P., Salzen, K. V., Lohmann, U., Lesins, G., Spacek, L., Zhang, L. M., Girard, E., Lin, H., Leaitch, R., Leighton, H., Chylek, P., and Huang, P. Canadian Aerosol Module: A size-segregated simulation of at- 
mospheric aerosol processes for climate and air quality models 1. Module development, J. Geophys. Res., 108, 4007, doi:10.1029/2001JD002002, 2003a.

Gong, S. L., Zhang, X. Y., Zhao, T. L., McKendry, I. G., Jaffe, D. A., and Lu, N. M.: Characterization Of Soil Dust Distributions In China And Its Transport During ACE-ASIA 2. Model Simulation and Validation, J. Geophys. Res., 108, 4262, doi:10.1029/2002JD002633, 2003b.

Gong, S. L. and Zhang, X. Y.: CUACE/Dust - An Integrated System of Observation and Modeling Systems for Operational Dust Forecasting in Asia, Atmos. Chem. Phys., 8, 2333-2340, 2008, http://www.atmos-chem-phys.net/8/2333/2008/.

Hakami, A., Henze, D. K., Seinfeld, J. H., Chai, T. , Tang, Y., Carmichael, G. R., and Sandu, A.: Adjoint inverse modeling of black carbon during the Asian Pacific regional aerosol characterization experiment, J. Geophys. Res., 110, doi:10.1029/2004JD005671, 2005.

Henze, D. K. and Seinfeld, J. H.: Development of the adjoint of GEOS-Chem, Atmos. Chem. Phys. Discuss, 6, 10 591-10 648, 2006.

Hollingsworth, A. and Lonnberg, P.: The statistical structure of short-range forecast errors as determined from radio sonde data. Part I :the wind field, Tellus, 111-136, 1986.

Hu, X. Q., Lu, N. M., Niu, T., and Zhang, P.: Operational Retrieval of Asian Dust Storm from FY-2C Geostationary Meteorological Satellite and its Application to real time Forecast in Asia, Atmos. Chem. Phys., 8, 1649-1659, 2008, http://www.atmos-chem-phys.net/8/1649/2008/.

Huebert, B. J., Bates, T., Russell, P. B., Shi, G., Kim, Y. J., Kawamura, K., Carmicheal, G., and Nakajima, T.: An overview of ACE-Asia: Strateggies for quantifying the relationships between Asian aerosols and their climatic impacts, J. Geophys Res., 108, 8633, doi:1029/2003JD003550, 2003.

Kalnay, E.: Atmospheric modeling, Data assimilation and predictability, Press Syndicate of University of Cambridge, Cambridge, 2003.

Levin, Z., Ganor, E., and Gladstein, V.: The effects of desert particles coated with sulfate on rain formation in the eastern Mediterranean, J. Appl. Meteor., 35, 1511-1523, 1996.

Liu, D. C. and Noredal, J.: On the limited memory BFGS method for large scale optimization, Math. Program, 45, 503-528, 1989.

Lorenc, A. C.: Analysis methods for numerical weather prediction, Q. J. R. Meteor. Soc., 112, 1177-1194, 1986.

Lorenc, A. C.: Development of an operational variational assimilation scheme J. Meteor. Soc., 75, 1B, 339-346, 1997.

Menard, R. and Chang, L.-P.: Assimilation of Stratospheric Chemical Tracer Observation Using a Kalman Filter. Part II: Validation Results and Analysis of Variance and Correlation Dynamics, Mon. Weather. Rev., 128, 2672-2686, 2000a.

Menard, R., Cohn, S. E., Chang, L.-P., and Lyster, P. M.: Assimilation of Stratospheric Chemical Tracer Observation Using a Kalman Filter. Part I: Formulation, Mon. Weather Rev., 128, 2654-2671, 2000b.

Parrish, D. F. and Derber, J. D.: The national meteorological center spectral statistical interpolation analysis system, Mon. Weather. Rev., 120, 1747-1763, 1992.

Tegen, I. and Fung, I.: Contribution to the atmospheric mineral aerosol loading from land surface modification, J. Geophys. Res., 100, 18 707-18 726, 1995.
Uno I., Satake S., Gregory, R. C., Tang, Y. H., Wang, Z. F., Takemura, T., Sugimoto, N., Shimizu, A., Murayama, T., Cahill, T. A., Cliff, S., Uematsu, M., Ohta., S., Quin, P. K., and Bates, T. S.: Numerical study of Asian dust transport during the springtime of 2001 simulated with the Chemical Weather Forecasting System (CFORS) model, J. Geophys. Res., 109, D19S24, doi:10.1029/2003JD004222, 2004.

Uno, I., Wang, Z., Chiba, M., Chun, Y. S., Gong, S. L., Hara, Y., Jung, E., Lee, S.-S., Liu, M., Mikami, M., Music, S., Nickovic, S., Satake, S., Shao, Y., Song, Z., Sugimoto, N., Tanaka, T., and Westphal, D. L.: Dust model intercomparison (DMIP) study over Asia: Overview, J. Geophys. Res., 111, D12213, doi:10.1029/2005JD006575, 2006.

Wang, Y. Q., Zhang, X. Y., Gong, S. L., Zhou, C. H., Hu, X. Q., Liu, H. L., Niu, T., and Yang, Y. Q.: Surface observation of sand and dust storm in East Asia and its application in CUACE/Dust forecasting system, Atmos. Chem. Phys., 8, 545-553, 2008, http://www.atmos-chem-phys.net/8/545/2008/.

William, D. C., Philip, J. R., Brian, E. E., Boris, V. K., and Lamarque, J.: Simulating aerosols using a chemical transport model with assimilation of satellite aerosol retrievals: Methodology for INDOEX, J. Geophys. Res, 106, 7313-7336, 2001.

Yang, Y. Q., Hou, Q., Zhou, C. H., Liu, H. L., Wang, Y. Q., and Niu, T.: Sand/dust Storms over Northeast Asia and associated largescale circulations in spring 2006, Atmos. Chem. Phys., 8, 25-33, 2008, http://www.atmos-chem-phys.net/8/25/2008/.

Yumimoto, K. and Uno, I.: Adjoint inverse modeling of CO emissions over the East Asian region using four dimensional variational data assimilation, Atmos. Environ., 40, 6836-6845, 2006.

Yumimoto, K., Uno, I., Sugimoto, N., Shimizu, A., and Satake, S.: Adjoint inverse modeling of dust emission and transport over East Asia, Geophys. Res. Lett, 34, L08806, doi:10.1029/2006GL028551, 2007.

Zender, C., Bian, H. and Newman, D.: Mineral Dust Entrainment and Deposition (DEAD) model: Description and 1990s dust climatology, J. Geophys. Res., 108, doi:10.1029/2002JD002775, 2003.

Zhang, H., Xue, J. S., Zhuang, S. Y., Zhu, G. F. and Zhu, Z. S.: Idea experiments of GRAPES three dimensional variational data assimilation system, ACTA. Meteor. Sinica, 62, 31-41, 2004.

Zhang, X. Y., An, Z. S., and Cao, J. J.: Dust emission from Chinese desert sources linked to variations in atmospheric circulation, J. Geophys. Res., 102, 28 041-28 047, 1997.

Zhao, T. L., Gong, S. L., Zhang, X. Y., and McKendry, I. G.: Modelled size-segregated wet and dry deposition budgets of soil dust aerosol during ACE-Asia, 2001: Implications for Trans-Pacific Transport, J. Geophys. Res., 108, 8665, doi:10.1029/2002JD003363, 2003.

Zhou, C. H., Gong, S. L., Zhang, X. Y., Wang, Y. Q., Niu, T., Liu, H. L., Zhao, T. L., Yang, Y. Q., and Hou, Q.: Development and Evaluation of an Operational SDS Forecasting System for East Asia: CUACE/Dust Atmos. Chem. Phys., 8, 787-798, 2008, http://www.atmos-chem-phys.net/8/787/2008/.

Zhuang, S. Y., Xue, J. S., Zhu, G. F., Zhao, J., and Zhu, Z. S.: GRAPES global 3D-Var system-Basic scheme design and single observation test, Chinese J. Atmo. Sci, 29, 872-884, 2005. 